\title{
CONTAGEM E CONTAC̣ÃO: NOTAS SOBRE CONTAR O TEMPO NA MODERNIDADE
}

\section{COUNT AND TELL: NOTES ABOUT TELLING TIME IN MODERNITY}

RESUMO: A intenção do ensaio é propor uma distinção entre dois modos de contar o tempo a partir de sua experiência na Modernidade e sua relação intrínseca com as transformações dos modos de produçãopercepção. Como os modos de contar são, em sentido amplo, assunto de disciplinas diversas, a abordagem escolhida é multidisciplinar, acolhe reflexões e passagens tanto de textos literários, quanto de reflexões teóricas do campo da História. A distinção proposta entre contagem e contação leva em conta o processo de "modernização" global e os espaços e momentos de resistência a esta modernização. Nestes últimos espaços reside, seja através de sua versão tradicional, seja através de sua versão mais modernista, o que se chamará aqui de contação, um modo de experienciar e expressar o tempo que não se submete completamente à lógica numérica e seriada instaurada a partir do tempo da fábrica como temporalidade normativa.

Palavras-chave: Modernidade; escrita da história; teoria literária.

ABSTRACT: The essay aims to suggest a distinction between two ways of telling time from the perspective of its experience in Modernity and its intrinsic relation to the transformation of the means of productionperception. Since the ways of telling are, broadly speaking, subject of different fields, the chosen approach is multidisciplinary, thus containing concepts and excerpts from both literary material and more theoretical reflections from the field of History. The proposed distinction between "count" and "tell" take in consideration the global process of "modernization" and the spaces and moments of resistance to this modernization. In these last places resides, either in its traditional version, or in its more modernist version, what will be called here "telling", a way of experiencing and expressing time that does not submits

${ }^{1}$ Pós-doutorando no Departamento de Teoria e História Literária da Universidade Estadual de Campinas - UNICAMP. 
itself completely to the numerical and seriated logic established since the time of the fabric became the normative temporality.

Keywords: Modernity; writing of history; literary theory.

O tempo passa e é sentido. Entre o verbo na ativa e na passiva está posicionada a vida humana. Porque embora seja razoável supor que há um tempo objetivo, como descrito pela física, sua experiência é subjetiva, não apenas no nível do indivíduo, mas como construção social. A forma com que cada agora se relaciona com os momentos do passado e do futuro, embora sejam todos igualados do ponto de vista da cronologia, do ponto de vista da percepção individual e coletiva eles variam tanto em intensidade (ao invés de quantidade) como em ordenamento (com outras possibilidades que não apenas a seriada). No prefácio a Futuro passado, Reinhart Koselleck distingue entre estas duas formas:

A cronologia - como ciência auxiliar que é - responde às questões sobre datação à medida que anula as diferenças entre os inúmeros calendários e medidas de tempo empregados ao longo da história, reunindo-os em um único tempo, regido segundo o nosso sistema planetário e calculado segundo as leis da física e da astronomia. [...] Mas esse pressuposto natural, contido em nossa divisão do tempo, será estranho à investigação da coincidência entre história e tempo, se é que se pode falar da existência de algo como um "tempo histórico" (2006, p. 13).

Esta não coincidência entre história e tempo, este entendido no sentido estritamente cronológico, parece, no entanto, ter sido posta em questão no período chamado Modernidade. Com a expansão cada vez mais total dos modos de produção e vida modernos pelo globo, os povos foram se esquecendo de que existem tantas maneiras de contar o tempo, quanto de experienciá-lo. As distintas formas comunitárias de contar o tempo foram aos poucos sendo substituídas por uma normatização global. Matematizado, ou seja, tendo cada diferente momento igualado a outros do passado e do futuro, o tempo foi reduzido de sua versão infinita, a experiência dos coletivos humanos, ao tempo seriado da fábrica.

Sobre a "invenção" do tique-taque, o som contínuo do relógio de pêndulo inventado por Christiaan Huygens em 1656, que parece vibrar com intervalos regulares e não variados como seus antecessores menos 
Contagem e contação: notas sobre contar o tempo na modernidade | 21

sofisticados, Stuart Sherman traça uma imagem sensível do que significou na psicologia social e, como seu estudo Telling Time ("Contando o tempo") mostra com profundidade, como as maneiras de contar o tempo mecânico modificaram a maneira de contar histórias na literatura, nos jornais e nos diários do século XVII na Inglaterra. Ela mostra como o tempo coletivo era marcado à distância e intermitentemente pelos relógios de Igreja e como, com a inovação dos relógios de Huygens, o tempo passou a ser medido de forma "contínua", não apenas nas praças públicas, mas nos interiores e, em breve, junto a cada proprietário de um relógio de pulso. Houve uma sincronização social em grau inédito e também muito mais precisa já que, antes dos pêndulos, os relógios contavam apenas com o ponteiro das horas. Os relógios de pêndulo inseriram não apenas o segundo ponteiro dos minutos, mas já em 1670 o terceiro, dos segundos. Com a multiplicação dos relógios e de seus visores deu-se também uma transformação na sensibilidade da percepção do tempo. Se os relógios das igrejas anunciavam as horas na distância através do som dos sinos, os ponteiros próximos dos relógios de pêndulo inseriram também o elemento visual.

O livro de Sherman traça também uma instigante relação entre a ascensão dos medidores modernos de tempo, entre a cronometria dos relógios, e as formas históricas e literárias de contar o tempo, sua cronografia. Sua abordagem é distinta da que se pretende estabelecer aqui, ou seja, estes polos não são diretamente relacionáveis ao que se chamará de contagem e contação, mas vê quase uma complementaridade entre certos gêneros literários, especialmente aqueles mais ligados à marcação do tempo, como o diário e a crônica, e a ascensão de uma nova sensibilidade do tempo que estas formas de literatura tentavam justamente "humanizar". De qualquer forma, a história material dos relógios e sua instigante relação com a literatura aponta para o gesto de reação da literatura modernista à concepção moderna de tempo, com seu movimento linear e homogêneo, e sua insurgência contra ela:

O relógio de Huygens lida sistematicamente com as unidades artificiais de minuto e segundo que os instrumentos eles mesmos efetivamente criam (nenhum antes deles tinha realmente "produzido" minutos); diários e jornais operam sistematicamente na unidade aparentemente natural do dia. [...] A coincidência histórica chocante com a qual a Inglaterra, do fim do século dezessete ao século dezoito, engendrou desenvolvimentos 
massivos e célebres ambos no tempo Huygensiano e em formais temporais narrativas sugere uma relação sem especificar qual ${ }^{2}$ (1996, p. 9)

Cabe menos, no entanto, falar de uma "humanização" da temporalidade moderna através da literatura, do que de uma interiorização, tanto no sentido de uma disciplina social através do relógio da fábrica, quanto das adaptações do aparelho sensível a partir do desenvolvimento de formas estéticas que dão conta da nova sensibilidade do tempo. É razoável imaginar que assim como uma língua não produzirá uma palavra para um referencial que desconhece, tampouco uma cultura produzirá uma forma de contar o tempo que não diga respeito às suas práticas de produção. Que interessa para o industriário um conceito ou uma narrativa para descrever as diversas eras míticas de criação da Terra e dos homens? Que interessaria as ideias de bater ponto ou de banco de horas a grupos que produzem de forma coletiva para subsistência? Em um ensaio sobre a modificação da percepção da passagem do tempo por trabalhadores ingleses durante o processo de industrialização no fim do século XVIII, o historiador inglês E. P. Thompson dá exemplos interessantes de formas de contar o tempo antes ainda da inserção dos relógios cheios de minutos dos capatazes da fábrica: "Os nativos de Cross River dizem: 'O homem morreu em menos tempo do que leva o milho para assar', menos de quinze minutos. [...] Um terremoto foi escrito em 1647 como tendo durado o tempo de dois credos; enquanto o cozimento de um ovo podia ser estimado por uma Ave-Maria rezada em voz alta" (1998, p. 270). Paulo Arantes comenta este início de expansão planetária da nova temporalidade e seus espaços "brancos" ${ }^{3}$, onde se vive, ainda, fora deste tempo, em outra temporalidade:

Neles é que se vive verdadeiramente na "hora do mundo", ao passo que outras realidades, outros espaços lhe escapam, alheios à batida desse relógio mais impositivo. É assim que podemos encontrar por toda parte zonas em que o "tempo do mundo" não repercute, "zonas de silêncio, de ignorância tranquila” - mesmo nas Ilhas Britânicas da

${ }^{2}$ As traduções, quando não indicadas de outro modo, são de minha responsabilidade.

3 O termo é quase irônico. Melhor seria dizer espaços "não-brancos" ou espaços onde o "branco" não chegou. 
Contagem e contação: notas sobre contar o tempo na modernidade | 23

Revolução Industrial. [...] São as imensas manchas brancas no mapa da vida material e econômica que permanecem à margem da "história triunfante" (2014, pp. 2-3).

Este exemplo de modos de tradicionais de contar o tempo, justamente no coração moderno que começava a bombear sua temporalidade própria para o resto do globo, também foi apropriado como material pela literatura em sua tentativa de lidar, reproduzindo e/ou opondo-se à nova temporalidade. Outros gêneros além da crônica e do diário participaram deste processo, sobretudo o gênero literário filho por excelência da Modernidade, o romance. Em Iracema de 1865, José de Alencar buscou duplamente, a partir da pesquisa histórica tradicional e da criação literária, dar conta do que seria uma maneira não-moderna de contar a passagem do tempo entre os ameríndios. Três dias aparecem no romance como "três sóis", uma tarde é dita "antes que o dia morra", o mês que passou se diz "a Lua cresceu". Passagens de tempo mais específicas são marcadas de acordo com sua duração, podendo ser "até que as sombras da montanha se estenderam pelo vale", quando "só havia sol no bico da arara" ou "todas as vezes que o cajueiro florescer". Além de caracterizar mais verossimilhantemente seu espaço literário, José de Alencar se aproveita desta forma de contar a passagem do tempo como estratégia narrativa para apresentar com ela a passagem no tempo interior dos personagens. Trata-se de um tempo que não é ainda alienado daqueles que o contam, mas que é nomeado também em sua relação com eles, um tempo da "equiparação da psicologia das personagens, da lógica da existência e da passagem do tempo com os movimentos e ciclos da natureza" (CAMILO, 2007, p. 171). Assim, diz o narrador, "a alegria ainda morou na cabana, todo o tempo que as espigas de milho levaram a amarelecer". Entre a Iracema bravia do começo da narrativa e a Iracema melancólica do fim dilata-se também a contação dos dias: ela passava "os já tão breves, agora longos sóis, na praia, ouvindo gemer o vento e soluçar as ondas". (ALENCAR, 1994, p. 56)

Uma posição literária sintomaticamente diversa em relação ao novo contar do tempo é a do narrador-personagem Robinson Crusoé no romance homônimo de Daniel Defoe de 1719. Exilado da chamada civilização em uma terra nova, uma ilha na América do Sul, o personagem perde à princípio a contagem do seu tempo social, com relógio e calendário gregoriano, tempo mecânico, homogêneo e repetitivo, caindo em um tipo de vivência narcótica do tempo, apenas para em seguida reconstruir triunfante a Inglaterra e o espaço-tempo do Ocidente 


\section{4 | Tomaz Amorim Izabel}

moderno em miniatura na ilha, da qual se considera colonizador e dono. A obsessão de Robinson pela marcação do tempo, dos dias que não podiam passar sem serem cuidadosamente contados, até a nomeação do nativo, sua única companhia na ilha, com um dia da semana, Friday, é metonímia poderosa do processo de disciplinamento colonial da temporalidade moderna pela qual passarão as comunidades e sociedades ameríndias. Os dias do seu calendário são marcados em uma cruz de madeira. Em um estudo sobre a temporalidade "agonizante" do romance inglês do século XVIII, Christine Mazurkewycz comenta a relação quase paranoica de Crusoé com o contar do tempo:

O retorno abrupto e compulsivo de Crusoé de seu estado flutuante de liberdade introspectiva para seu contar ["accompt"] medido do calendário é exemplar da distinção que Bergson estabelece entre tempo como qualidade (imediata) e tempo como quantidade (medido). A ansiedade e o equívoco confessados por Crusoé sobre a possível perda de um dia - "e sem nunca saber como" - é uma quantificação do tempo que chega às custas da "pureza original" do tempo (2013, p. 149).

Se se tomar a Revolução Francesa como um dos acontecimentos políticos fundadores da Modernidade, é interessante notar como - no espírito de toda revolução que quer se perpetuar através da repetição da interrupção que ela julga ter instaurado - ela instaura não apenas um regimento político, mas também um novo calendário que tem como data inicial o próprio início, a data da proclamação da República Francesa, não mais baseado nas tradições ultrapassadas com as quais se queria romper, mas baseado numa ideia de racionalidade e utilidade. Ou seja, a contagem do tempo passa a ser orientada a fins, é instrumentalizada a partir das necessidades produtivas do mundo recém-instaurado do trabalho moderno. Neste sentido, trata-se de uma manifestação exemplar do espírito mais burguês. Os nomes dos meses não fazem mais referência a divindades ou reis da Antiguidade, mas aos ciclos da natureza mais apropriados para o plantio e a colheita: Vindemiário, mês da colheita de uvas, Germinal, mês da germinação, etc. Os dias da semana também deixam de homenagear os deuses nórdicos e passam a ser apenas números ordenados: primidi, duodi, trididi, etc. Troca-se o sete mítico dos dias da semana por dez, base do sistema numérico, muito mais prático para a contagem. O mesmo se dá com os dias que passam a contar com dez 
Contagem e contação: notas sobre contar o tempo na modernidade | 25

horas, compostas de cem minutos de cem segundos. Tudo muito mais calculável, mais facilmente divisível, ao gosto, portanto, racional e instrumental da Modernidade.

Mas talvez, como toda fundação de temporalidade, a pretensão de eternidade e a retroinvenção moderna revelam-se também datadas historicamente, mutáveis e, no limite, vulneráveis a novas fundações. $\mathrm{O}$ calendário revolucionário foi instaurado dois anos depois da revolução e revogado apenas doze anos depois. Lembrete agudo de que as temporalidades são históricas, tanto as tradicionais, quanto as modernas. O momento de destruição do calendário estabelecido parece durar apenas até que se instaure um novo, contradição inicial e permanente de toda revolução bem-sucedida (pelo menos na esteira do ensaio Crítica da violência, de Walter Benjamin). Rebecca Comay (2016) comenta esta ironia a partir do exemplo histórico da Revolução Francesa, mas com consequências para movimentos revolucionários em sentido mais amplo:

Como o relógio decimal de curta duração, a semana de 10 dias, ou o novo calendário republicano que foi introduzido tardiamente, no Ano II, por ordem da Convenção (depois de semanas e meses de vacilação sobre quando a nova era realmente começou, o que serviria para marcar o início, que poderia estabelecer os termos de mediação, e o que exatamente era para ser comemorado), a Revolução imediatamente se tornou obsoleta.

Vê-se que contar o tempo não tem nada de arbitrário ou de desinteressado, trata-se de uma manifestação cultural, política e metafísica de importância fundamental para a organização social da vida. A crise temporal moderna, se se puder falar assim, parece vir da substituição dos inúmeros modos de contar, produzidos pelos diversos coletivos através de suas necessidades histórico-literárias, por um único global na esteira da vitória de um único modo de produção. É para tentar lidar com esta transformação que se propõe então a distinção entre os dois modos que, sem querer fossilizar seu estado vivo, tenta apontar tendências, polos orientadores com características específicas e antagônicas, ainda que se toquem e misturem das maneiras mais interessantes através da história e da literatura.

As formas de contar, com o duplo sentido, mais apropriado para levar em consideração sua transformação, variam de acordo com a necessidade histórica dos grupos que irão contá-lo. Em português, contar 


\section{6| Tomaz Amorim Izabel}

tem um significado duplo que poderia ser resumido em um modo numérico e um modo narrativo. Contam-se coisas e contam-se histórias. O tempo, entrelaçamento das histórias das coisas, também é contado. Mas enquanto a contagem numérica conta iguais, a contação narra diferentes. Deleuze lembra como Pius Servien distinguia entre duas linguagens: "a linguagem das ciências, dominada pelo símbolo da igualdade, onde cada termo pode ser substituído por outros, e a linguagem lírica, em que cada termo, insubstituível, só pode ser repetido" (2006, p. 12). Ou para aproveitar a duplicidade do português, o contador: uma mesma palavra para duas funções bastante diferentes na Modernidade - o contador financeiro e o contador de histórias, um que faz conta, e outro que faz de conta. Henri Bergson, ao investigar o que julga serem distorções na representação da sensação do tempo, dá um exemplo canônico:

Não basta dizer que o número é uma colecção de unidades; há que acrescentar que estas unidades são idênticas entre si ou, pelo menos, que as supomos idênticas desde que as contemos. É claro que ao contarmos as ovelhas de um rebanho diremos que tem cinquenta, embora se distingam umas das outras e o pastor as conheça facilmente; mas é porque se concorda em deixar de lado as suas diferenças individuais para só ter em consideração a sua função comum (1988, p. 58).

Assim, só se pode contar numericamente unidades igualadas. A tentativa de tomar os números não como mera acumulação abstrata de unidades iguais, mas como distintos, cada um em sua "identidade" e significado próprios, não é contagem, mas numerologia. As próprias filosofia e matemática demoraram alguns séculos para distinguir entre o número como qualidade e como quantidade. Aristóteles dá como exemplo na Metafísica a correspondência estabelecida pelos pitagóricos entre número e coisas: o feminino como o dois, o masculino como o três e o casamento, como soma de ambos, como cinco, a justiça como o quatro (produto de dois fatores iguais), a alma como o um (princípio indivisível), o tempo como sete, etc ${ }^{4}$. Funes, o memorioso, célebre personagem de Jorge Luis Borges, tem a capacidade sobre-humana de

${ }^{4}$ Cf. Aristóteles $(1984$, p. 21$)$ e as respectivas notas de Joaquim de Carvalho. 
Contagem e contação: notas sobre contar o tempo na modernidade | 27

guardar na memória com perfeição tudo o que vê e pensa. Funes processa o mundo como pura diferença, conhece apenas a contação e nada da contagem. "Perturbava lhe que o cão das três e catorze (visto de perfil) tivesse o mesmo nome que o cão das três e quatro (visto de frente)" (2007, p. 107). Segundo o narrador do conto, Funes "era quase incapaz de ideias gerais, platônicas". Talvez por isso tenha se recusado a contar usando um sistema de base decimal, que se repete abstratamente, e tenha inventado um sistema numérico ao modo da contação em que cada número (e consequentemente cada coisa em cada momento sob cada aspecto) tem estranhamente um nome próprio:

Em lugar de sete mil e treze, dizia (por exemplo) Máximo Pérez; em lugar de sete mil e catorze, A Ferrovia; outros números eram Luis Melián Lafinur, Olivar, enxofre, os rústicos, a baleia, o gás, a caldeira, Napoleão, Agustín de Vedia. [...] Eu lhe observei que dizer 365 era dizer três centenas, seis dezenas, cinco unidades; análise que não existe nos "números" O Negro Timoteo a manta de carne. Funes não me entendeu ou não quis me entender (idem, p. 106).

Talvez, neste momento, se pudesse distinguir da seguinte forma: a contagem, como numérica, abstrai a diferença, em oposição à contação, como narrativa, que a privilegia. Esta separação é importante para pensar o tempo na Modernidade porque segundo Bergson, devido ao caráter necessariamente cumulativo da numeração, a contagem se dá sempre no espaço e não no tempo:

É possivel perceber, no tempo, e apenas no tempo, uma sucessão pura e simples, mas não uma adição, isto é, uma sucessão que viesse a dar numa soma. De facto, se uma soma se obtém pela consideração sucessiva de diferentes termos, ainda é necessário que cada um destes termos persista quando se passa ao seguinte e espere, por assim dizer, que lhe acrescentemos os outros: como esperaria ele, se não passasse de um instante da duração? E onde esperaria, se não o localizássemos no espaço? Involuntariamente, fixamos num ponto do espaço cada um dos momentos que contamos, e é apenas com esta condição que as unidades abstractas formam uma soma. 
[...] Toda a ideia clara do número implica uma visão no espaço (1988, p. 59-60).

Em outras palavras, se o tempo passa, ele não se detém. Mas para que haja sua contagem e, portanto, sua acumulação (o número três, por exemplo, não é nada mais do que o acúmulo de três unidades idênticas, de três "uns"), ele precisa se deter para que o próximo momento se junte a ele. Já que o tempo passa e não se detém, é necessária uma abstração espacial para que ele se acumule e seja contado. Bergson chamou este processo de espacialização do tempo e este termo (adotado posteriormente, com sentido diverso, pela teoria pós-moderna) é interessante para pensar justamente a vitória histórica da contagem sobre a contação na Modernidade e a perda cada vez maior da dimensão temporal na experiência moderna, substituída por sua dimensão espacial.

Mas a ascensão da contagem em detrimento das inumeráveis formas de contação não se deu arbitrariamente. Ela possui como base material a transformação dos modos de produção e da própria forma mercadoria. Seria possível, para aproximar a sensibilidade temporal dos modos de produção, estabelecer uma relação entre este par de conceitos e os conhecidos conceitos de valor de troca e valor de uso como desenvolvidos por Karl Marx já no primeiro volume d'O Capital. Enquanto o valor de uso da mercadoria se refere às suas propriedades materiais únicas, à sua utilidade "determinada pelas propriedades do corpo da mercadoria" (1996, p. 166), o valor de troca estabelece uma igualdade abstrata entre coisas diferentes, como, por exemplo, quantidades de ferro e trigo. $\mathrm{O}$ fato de que elas possam ser trocadas a partir da mediação de um mesmo valor mostra que "ambas são, portanto, iguais a uma terceira, que em si e para si não é nem uma nem outra. Cada uma das duas, enquanto valor de troca, deve, portanto, ser redutível a essa terceira" (IDEM, p. 167). Para voltar ao exemplo das ovelhas, o valor de troca estabelece uma relação de igualdade abstrata entre elas e quaisquer outras "mercadorias", enquanto o valor de uso atentaria para suas características específicas (e sua história única) impossíveis de serem igualadas ou repetidas por outras coisas ou por outras ovelhas.

Vê-se assim como a ascensão do valor de troca sobre o valor de uso do ponto de vista econômico pode ser relacionada com a ascensão da contagem sobre a contação do ponto de vista histórico-literário. O valor de troca é uma operação alquímica que transforma diferentes em iguais, da mesma forma como dentro da fábrica, se se pensar na forma de pagamento de salário por hora trabalhada, não há diferença entre o que 
se produz, por quanto tempo, por quem, seu estado físico, a estação do ano, a posição das estrelas no céu... Georg Simmel, que dedicou longos trabalhos à questão do dinheiro na sociedade moderna, faz, inicialmente, um elogio da racionalidade do cálculo e sua previsibilidade. Os modos de contar dinheiro e tempo que se imbricam na ideologia moderna como nunca na história da humanidade são vistas pelo sociólogo com certo otimismo. Em Filosofia do dinheiro, ele afirma: "A determinação do tempo abstrato pelo relógio, assim como a do valor abstrato pelo dinheiro, proporciona um esquema mais fino e seguro de divisões e medidas que, assumindo em si os conteúdos da vida, confere a eles, pelo menos do ponto de vista da prática externa, uma transparência e uma calculabilidade de outro modo inatingível” (SIMMEL). Mas esta vantagem da calculabilidade tem como custo justamente a diversidade que uma temporalidade baseada no dinheiro não pode aceitar. Custo esse que não é mínimo, mas máximo, na verdade, "impagável", pelo rebaixamento brutal e generalizado que opera - a troca da infinitude concreta do mundo por sua representação abstrata em miniatura. Nas palavras do próprio Simmel, em outro trabalho:

De fato, as coisas mesmas são também desvalorizadas, num sentido mais geral, pela equivalência com aquele meio da troca válido para qualquer coisa. O dinheiro é "vulgar" porque é o equivalente para tudo e para todos; somente o individual é nobre; o que corresponde a muitas coisas corresponde ao mais baixo entre elas e reduz, por isso, também o mais alto para o nível do mais baixo. [...] Assim, o valor mais específico das coisas fica prejudicado pela possibilidade constante da transformação do mais heterogêneo em dinheiro. E a língua tem razão, por isso, quando chama de "impagável" o que é muito especial e assinalado (1998, p. 31).

Contar o tempo como se conta dinheiro tem, portanto, alto custo. A relação entre os dois tipos de contar, se vista de maneira dialética, aponta para uma "vulgarização" moderna, para usar o termo de Simmel, em relação ao contar. O problema parece estar em contar da mesma maneira coisas que são incomparáveis - objetos no espaço e acontecimentos no tempo, por exemplo. Ordenar uma história como se ordena uma escala numérica. Tratar valores como personagens e personagens como valores. É contar de maneira não-dialética, como se o 


\section{0 | Tomaz Amorim Izabel}

contado não influenciasse, exigisse, a partir de sua especificidade material, o modo de sua contagem/contação.

A própria história dos termos nas línguas europeias aponta para uma tensão constante entre os dois modos. Já na origem da narrativa e do pensamento histórico-literários gregos eles aparecem relacionados. Segundo Maria da Rocha Pereira, o logos ( $\lambda$ ó $\gamma$ os), relacionado posteriormente à reflexão, discussão e argumentação filosóficas, no início tinha proximidade com o verbo "colher" e "reunir". "Do sentido de 'reunir' se passa facilmente ao de 'fazer a contagem'. E neste ponto começa a bifurcação semântica": de um lado o termo evolui para "contar enumerar - narrar" e do outro para "conta - cálculo - reflexão - discussão argumentação" (2012, p. 241).

Também nas línguas latinas as diversas variações de contar têm como origem o termo computare, que originalmente se referia apenas ao contar numérico (e deu origem ao onipresente computador, contadormor responsável pela contagem contemporânea). As diversas línguas latinas desenvolveram o contar narrativo a partir deste numérico, como no caso do espanhol que, assim como o português, mantém contar com o duplo sentido. Já no italiano os termos permaneceram separados como contare e raccontare e no francês compter e conter. As línguas germânicas vão por um caminho parecido. $\mathrm{O}$ verbo erzählen em alemão é formado pelo prefixo er- e pelo radical zählen que significar contar, no sentido numérico. O verbo zählen por sua vez tem como radical o termo Zahl, número, que possui uma ascendência que vai até o distante del do protoindogermânico, este que, já então, continha o duplo sentido de contar numérico e narrativo, passando pelo talō protogermânico que ainda mantém os dois sentidos (e que dá origem ao termo inglês tell, contar, raiz do termo Storyteller, contador de histórias), dando origem a zala e zalōn do altoalemão antigo quando se dividiram com os sentidos, respectivamente, de ordenar numericamente e contar uma história, dando origem então aos zählen e o erzählen do alemão contemporâneo.

Para voltar do nível etimológico ao histórico mais amplo, se nas línguas européias, histórica e etimologicamente, a contagem deu origem à contação, a Modernidade é o período histórico em que esta relação quebra como uma onda e toma o sentido contrário: as intensidades históricas, distintas qualitativamente umas das outras, são socialmente transformadas em quantidades. As diversas formas tradicionais da contação do tempo se converteram aos poucos em uma única forma numérica de contá-lo que se caracteriza por possibilidades matemáticas: 
primeiro, de rebaixamento a um mesmo igual, depois, de repartição em pedaços cada vez mais "precisos", ou seja, menores. Nos modos de produção organizados ainda em torno dos ritmos naturais (luz do sol, estações do ano, marés, ciclos de colheita, etc.), geralmente não há necessidade de contar o tempo dividindo-o, por exemplo, em períodos menores do que uma hora. Em uma passagem sintomática de A ética protestante e o "espirito" do Capitalismo, Max Weber aponta para a presença desta subdivisão e aceleração do tempo justamente na literatura: "Estamos acostumados a encará-lo como característico ao homem moderno que não tem tempo, ou, por exemplo, como Goethe em Wanderjahren, a medir o grau de desenvolvimento capitalista pelo fato de os relógios tocarem a cada quarto de hora" (2001, p. 161).

A fragmentação do tempo, a necessidade de medi-lo em quantidades sempre menores, é sintoma claro de sua aceleração. Não há tempo livre, cada pequena, menor parte, precisa ser capturada, medida e instrumentalizada. Para as máquinas de precisão, os atletas profissionais e os especuladores da bolsa de valores os segundos e suas frações são a unidade comum da experiência do presente. A angústia generalizada e o déficit de atenção como epidemia global parecem ser o preço pago por uma sensibilidade ainda humana em um mundo cada vez mais além da experiência imediata humana, sobretudo do ponto de vista da experiência do tempo.

Os exemplos "tradicionais" de Thompson citados anteriormente estão em oposição, em conflito, com o processo de disciplinamento dos trabalhadores ingleses. São estas concepções de tempo que serão objeto da nova disciplina temporal, imposta violentamente pelos estados e pela burguesia financeira e industrial, ou pela burocracia partidária, que os comanda. A temporalidade não se molda mais tão lentamente quanto o processo de surgimento e vigência de uma língua ou de uma cultura ao redor do ritmo tradicional de reprodução material da vida dos coletivos, mas é imposta a partir de cima, por uma ordem que se instalava rapidamente ao redor do globo. As maneiras de contar o tempo não servem mais aos interesses comunitários, mas aos interesses privados e internacionais dos donos de fábrica. Eles, que, como Thompson mostra, tornaram-se senhores, literalmente, do tempo, que não detinham monopólio apenas dos meios de produção, mas dos meios de medição do novo tempo social, vantagem comercial e política incalculável, já que únicos detentores de equipamentos de medição normativa e "precisa" do tempo - o relógio. O exemplo seguinte, retirado direto do livro de 
instrução de um supervisor, aponta para o conflito temporal do novo tempo:

Considerando as informações que tenho recebido de que vários empregados do escritório são tão injustos a ponto de calcular o tempo pelos relógios que andam mais rápido, o sino tocando antes da hora do fim do expediente, e pelos relógios que andam mais devagar, o sino tocando depois da hora do início do expediente, e que esses dois traidores Fowell e Skellerme têm conscientemente permitido tal coisa: fica determinado que a esse respeito nenhuma pessoa deve calcular o tempo por nenhum outro relógio de parede, sino, portátil ou relógio de sol que não seja o do supervisor, o qual só deve ser alterado pelo guarda do relógio (1998, p. 290),

Fala-se aqui de temporalidade moderna, em sentido amplo, e não meramente de temporalidade capitalista, porque, embora ela tenha surgido com a ascensão do capitalismo como modelo econômico global, a aceleração do tempo e sua calculabilidade matemática, sua contagem, não foi e não é exclusividade dos regimes e ideologias estritamente capitalistas. $\mathrm{O}$ aceleracionismo e desenvolvimentismo que marca certo pensamento marxista e, seguramente, projetos políticos de países comunistas no século $\mathrm{XX}$ reproduziu quase sem crítica nenhuma esta nova temporalidade. Um registro histórico escrito por um escritor engajado como Walter Benjamin ajuda a entender. Em Imagens de Pensamento de 1927, ele descreve algumas impressões de sua visita recente a Moscou. Seu interesse, além das questões pessoais da viagem, é no impacto da revolução soviética na vida cotidiana das pessoas e seu potencial para o resto da Europa. Em um dos fragmentos mais instigantes, Benjamin descreve a nova relação dos operários com o tempo de forma semelhante com o processo descrito por Thompson. Ainda que com diferenças gritantes quanto à organização dos trabalhadores e seu papel no estado, o trabalhador russo também precisou ser disciplinado para uma nova sensibilidade do tempo moderno. Lá, assim como nas fábricas capitalistas, o relógio se torna instrumento indispensável. "Perdem tempo com tudo", afirma o alemão Benjamin em relação aos lenientes trabalhadores russos que cometem o pecado de usar o tempo como "uma aguardente ordinária da qual nunca se saciam", "embriagados pelo tempo". Cabe a intervenção, portanto, do Partido para que os trabalhadores percebam que "Tempo é dinheiro' - em cartazes 
Contagem e contação: notas sobre contar o tempo na modernidade | 33

reclama-se para essa frase admirável a autoria de Lenin, a tal ponto é estranha aos russos essa noção" (1987, p. 168). Que uma frase tornada célebre por Benjamin Franklin possa ser atribuída a Lenin em plena Rússia revolucionária, que se impute ao líder da Revolução Russa uma das frases mais distintivas da ideologia Capitalismo em sua relação com o tempo, isso aponta para o fato de que do ponto de vista da experiência do tempo pelo trabalhador, parece haver pouca diferença na nova experiência planificada do tempo entre capitalistas e soviéticos. Em 1913, Lenin chamou o Taylorismo de "escravidão do homem pela máquina". Em 1918, no entanto, ele sugeriu que adotar o Taylorismo, sob uma organização socialista, poderia ser uma medida progressista. A ideia era que aumentar a produtividade diminuiria o tempo de trabalho e permitia ao trabalhador soviético mais tempo para participar da vida no novo regime (cf. o primeiro capítulo de NOYS 2014). Paulo Arantes comenta, referindo a Wallerstein, o que chama de "inverossímil convergência geocultural" entre Americanismo Wilsoniano e Comunismo Leninista:

Ambos compartilhavam não só a plataforma ilustrada de engenharia social racionalmente planejada, mas também uma "visão secular do futuro", sendo igualmente, um e outro, "escatologias". Dessa liga intempestiva brotará - para chegar logo ao ponto final - a "fé geocultural na possibilidade do desenvolvimento", estrela-guia entre 1945 e 1970, desde então uma quimera em queda livre (2014, p. 16).

E embora isto seja claro hoje, como no exemplo do comunismo de mercado da China, no momento da visita de Benjamin à Rússia tratava-se de construir uma nova vida e uma nova sociedade com uma nova cultura, enfim, com outra concepção de tempo e história, não com uma simples aceleração permanente, um "Grande salto adiante" em perseguição ao ocidente "desenvolvido". Desenvolvido em relação a que? Desenvolvido em qual direção? Os trabalhadores russos em processo de industrialização ofereceram a mesma resistência ao processo de disciplinamento temporal que seus colegas ingleses e mexicanos descritos por Thompson:

Pois o que os moralistas mercantilistas disseram sobre o fato de os ingleses pobres do século XVIII não reagirem aos incentivos e à disciplinas é frequentemente repetido, por observadores e por teóricos do crescimento econômico, a 
respeito dos povos dos países em desenvolvimento na época atual. Assim os peões mexicanos nos primeiros anos deste século eram considerados um povo "indolente e infantil" (1998, p. 299).

Ainda a partir desta perspectiva do disciplinamento à temporalidade moderna, o antropólogo Pierre Clastres faz uma reflexão sobre acusações semelhantes, em contexto diverso, o da colonização, mas semelhantes do ponto de vista do disciplinamento temporal, em relação aos índios americanos e seu contato com os europeus horrorizados por seu excesso de tempo "ocioso":

Se na nossa linguagem popular dizemos "trabalhar como um negro", na América do Sul em contrapartida diz-se "preguiçoso como um índio". Então, das duas uma: ou o homem das sociedades primitivas, americanas e outras, vive em economia de subsistência e passa a maior parte do seu tempo à procura de alimento; ou então não vive em economia de subsistência e pode pois permitir-se lazeres prolongados fumando na sua cama de rede. Foi isso que espantou, sem dúvida, os primeiros observadores europeus dos índios do Brasil. Foi grande a sua reprovação ao constatarem que rapazolas cheios de saúde preferiam adornar-se como mulheres com pinturas e plumas, em lugar de transpirar nas suas hortas. Gentes que ignoravam que é preciso ganhar o pão com o suor do seu rosto (1979, p. 187).

Não há como negar que há algo deste gesto entusiasmado pela "marcha da civilização ocidental" nas observações de Benjamin sobre os

\footnotetext{
${ }^{5}$ No processo violento de unificação temporal há também uma unificação cultural, tanto do ponto de vista dos modos de trabalho, como de sua comunicabilidade. Vale a pena ressaltar, se é verdade que o global se tornou moderno, também é verdade que o moderno é, ao menos originalmente, ocidental, o que leva à importância de observar o nãoocidental, e seu potencial subversivo, portanto, em relação ao projeto da Modernidade. Como aponta Jacques Le Goff, em vocabulário diverso do que se usa aqui, o não-ocidental é também um não-moderno: "O primeiro embate total entre antigo e moderno foi, talvez, o dos índios da América
} 
Contagem e contação: notas sobre contar o tempo na modernidade | 35

trabalhadores russo que parecem resistir a este industrialismo leninista através da leniência:

Se, na rua, está sendo rodada a cena de um filme, se esquecem porquê e para onde estão indo, ficam acompanhando a filmagem por horas a fio e chegam agitados ao serviço. Assim, quanto ao uso do tempo, o russo continuará sendo por muito tempo "asiático". [...] A unidade de tempo é basicamente sistchas. Significa "imediatamente". Pode-se ouvir esta palavra, conforme o caso, dez, vinte, trinta vezes como resposta, e horas, dias e semanas se esgotam até que o assim prometido aconteça. [...] Tornam todas as horas riquíssimas, todos os dias exaustivos, transformam toda vida no momento (1987, p. 169).

Presos em sua relação "imediata" com o presente, sem o imperativo permanentemente mediador da necessidade de produzir e consumir, de "transpirar nas suas hortas", assim os não-modernos, chamados orientalisticamente pelo alemão Benjamin de "asiáticos", resistem ao novo tempo da cidade. É estranho que os operários russos não sejam vistos com o mesmo olhar elogioso dedicado ao flâneur francês benjaminiano que "com sua ostensiva serenidade, protesta contra o processo de produção” (1989, p. 171). O operário chega atrasado para o trabalho porque se interrompe no caminho para ver a gravação de um filme. Justamente o cinema, a arte da interrupção, que treinaria, segundo

com os Europeus, e as suas conseqüencias foram claras: os Índios foram vencidos, conquistados, destruídos e assimilados; raramente as várias formas de imperialismo e colonialismo, do século XIX e princípio do XX, tiveram efeitos tão radicais. As nações atingidas pelo imperialismo ocidental, quando conseguiram alcançar mais ou menos a sua independência, foram confrontadas com o problema do seu atraso em certos campos. A descolonização, posterior à Segunda Guerra Mundial, permite às novas nações que, por sua vez, abordem este problema. Quase todas as nações atrasadas se encontraram perante a equivalência entre modernização e ocidentalização e o problema do moderno foi posto paralelamente ao da identidade nacional. Um pouco por todo o lado distinguiu também a modernização econômica e técnica da modernização social e cultural”. (1990, p.184-185) 


\section{6 | Tomaz Amorim Izabel}

Benjamin, os sentidos do cidadão moderno para a vida na cidade grande, é que interrompe a caminhada do trabalhador para a fábrica.

Nos anos do regime stalinista, o que era um germe desenvolvimentista no contexto da Revolução se torna espírito da própria política soviética com seus Planos Quinquenais. Se o capital monetariza o tempo, sob Stalin há uma "nacionalização do tempo" e a aceleração das forças produtivas não se tornou tarefa apenas econômica, mas política e revolucionária. O progresso histórico, ou seja, o ritmo do tempo, é ditado pelas decisões políticas do ditador. O que, lido pelo oposto, significa que qualquer tentativa de desacelerar, conservar modos tradicionais ou respeitar a diversidade das temporalidades é contrarrevolucionária e, portanto, punível como tal. "Disciplina, obediência e conformidade para alcançar a "aceleração" (uskorenie) histórica necessária enquanto "diminuir o ritmo" (gromozhenie) se tornaria ato contrarrevolucionário” (2014, p. 28), como afirma Benjamin Noys em seu estudo sobre as origens do Aceleracionismo. Nas palavras de Susan Buck-Morss:

Traduzir a luta espacial entre cidade e campo nos termos do discurso temporal da luta de classes justificava a perseguição de camponeses como 'pessoas do passado'. Toda a resistência camponesa era definida como resistência de classe que desacelerava o curso da história. [...] $\mathrm{Na}$ década de 1920, ainda era possível argumentar que os povos indígenas do norte e do centro da Ásia tinham elementos de sociedade sem classe e de 'comunismo primitivo' que poderiam tornar a transição para o socialismo mais fácil. Mas por volta de 1930 toda sua cultura era vista como hostil à revolução e ao progresso histórico. [...] A equação entre tempo revolucionário e modernização econômica implicava uma obliteração necessária das culturas indígenas, da mesma maneira como fez com a classe camponesa tradicional (2000, p. 38).

Insere-se na Modernidade, portanto, nos regimes políticos mais diversos, o tempo da fábrica como "guarda do relógio", como norma do tempo social com a abolição progressiva de outras, incontáveis, formas de contá-lo. Que se tenha que fazer um esforço histórico crítico em busca de outras formas de contar já é prova do quanto avançou globalmente a contagem moderna. Buscar ou reinventar através de povos, culturas ou nichos não completamente "modernizados", outras formas de contar o 
tempo parece ser uma forma possível de resistir à perda desta diversidade. É importante lembrar: não há uma temporalidade a priori, uma forma de perceber e contar o tempo comum que não seja mediada biológica e socialmente por estruturas como os aparelhos fonadores, aparelhos de escrita e as próprias línguas, necessariamente inseridas num fluxo social vivo e em permanente transformação. Este é um dos postulados do próprio Walter Benjamin em sua análise das transformações da obra de arte com o advento tecnológico de sua reprodutibilidade: "No interior de grandes períodos históricos, a forma de percepção das coletividades humanas se transforma ao mesmo tempo que seu modo de existência. $\mathrm{O}$ modo pelo qual se organiza a percepção humana, o meio em que ela se dá, não é apenas condicionado naturalmente, mas também historicamente" (1987, p. 169). Uma das vantagens desta perspectiva é a superação da divisão tradicional (e artificial) entre economia e estética, entre modos de produção e modos de percepção. A vitória triunfal do modo de produção industrial traz consigo transformações radicais na forma de perceber o tempo e, consequentemente, de contá-lo.

Refletindo sobre as intersecções por vezes problemáticas entre as disciplinas Antropologia e História, Lilia Schwarcz aponta para as variações culturais no pensamento do tempo e da história: "Diante da experiência etnográfica, não há como entender história no singular" (2005, p. 120). Durante muito tempo, no entanto, a falta de documentos históricos em culturas iletradas lançou a etnografia em um eterno presente dos coletivos estudados. Uma possibilidade, segundo EvansPritchard referido por Schwarcz, seria entender a história não como uma sucessão de eventos, mas como “'a relação entre eles' [...] $\mathrm{O}$ antropólogo introduzia, dessa maneira, uma outra chave explicativa: história é processo, e não há sociedade sem história, mesmo que no tempo sincrônico" (2005, p. 123). O tempo seria um a priori humano, um universal, mas as culturas elaboram sua passagem, a relação entre os momentos, de formas diferentes, como mostram os exemplos de Schwarcz:

O tempo dos Nuer, que, como mostra Evans-Pritchard, adotavam um referencial interno; o tempo dos Mendi, um povo que, como explica M. Sahlins, fazia tudo convergir para si; o modelo pendular encontrado por Leach entre os Kachin, no qual o tempo é representado como uma repetição de inversões; o tempo dos Piaroa, descrito por J. Overing, o qual é ora linear ora não; o tempo dos Umeda, 
praticado no ritual pesquisado por Alfred Gell, quando se encenam com diferentes cores os vários ciclos da vida, e o "nosso" - um tempo seriado e cumulativo (2005, p. 121).

Como já dito, estas formas de contar diminuídas pela pretensão totalizadora do modo moderno encontram resistência não apenas nos povos tradicionais e em suas práticas cotidianas, mas em manifestações culturais modernas ou híbridas como a literatura. Os modernismos nas artes, por definição, nunca se renderam completamente e nunca puderam se render à contagem. A literatura está dentro da contação, ainda que mesclada com elementos de contagem do seu contexto de produção, como é o caso do já citado Borges, mas também de seu "precursor" tcheco Franz Kafka. Em sua obra e na de autores do mesmo período como Robert Musil, a estratégia em relação ao desaparecimento social da contação se dá através da paródia da contagem e de sua tomada até às últimas consequências, com o despedaçamento da estrutura espaçotemporal. Um dos exemplos mais evidentes deste procedimento está no círculo de narrativas chamado "Durante a Construção da Muralha da China" de 1917. Para contar uma história distante no espaço e no tempo, Kafka não escolhe um viajante, um cronista ou um historiador (à maneira do Erzähler que também para Benjamin já não existia mais), mas um tipo de engenheiro que descreve a construção de uma obra monumental e sua relação com o sistema social e político. Descrições detalhadas do exótico e sua relação com um narrador subjetivo dão lugar a um relatório de tom científico (que ele chama de Untersuchung) sobre o número de trabalhadores (quatro pedreiros e um arquiteto para cada quinhentos metros de muro construídos em cinco anos), a extensão do muro e um debate aprofundado que ocupa a maior parte do texto sobre a melhor estratégia de construção, se por partes isoladas ou linearmente. Esta enumeração, à princípio, é ordenada e subordinada à confiança em uma unidade, fornecida ora pela liderança (Führerschaft), ora pelo Imperador, ora pelo próprio sentimento de comunidade dos chineses.

Com o prosseguimento da contagem, no entanto, a lógica igualadora do número é levada até o infinito produzindo efeitos bizarros como a impossibilidade de contato entre espaços e tempos distintos. $\mathrm{O}$ projeto de construção do muro deixa de fazer sentido quando se considera que os invasores do Norte estão tão longe que, mesmo se viessem a toda velocidade com seus cavalos selvagens, nunca chegariam. Tampouco chega a mensagem imperial, vinda de Pequim, a ser entregue pelo mensageiro do imperador. A compreensão histórica das dinastias e 
das intrigas palacianas segue a mesma lógica: a história é tamanha e tão ancestral que sua divulgação dos grandes conhecedores até os súditos na periferia se embaralha. $\mathrm{O}$ pesquisador chega a dizer que a liderança da construção existe antes da própria China. $\mathrm{Na}$ aldeia na periferia do império: "Imperadores já falecidos há muito tempo são colocados no trono nas nossas aldeias, e, de um que já só sobrevive a canção, foi lida recentemente uma proclamação pelo padre em frente ao altar" (KAFKA, 2002, p.87). A ordenação numérica colapsa implodindo espaço-tempo e condenando os personagens ao absoluto aqui-agora da aldeia. Esta tomada da contagem até as últimas consequências pode ser entendida como representação literária do tempo social moderno: uma história quantitativa e não qualitativa, uma maneira de contar desligada das relações que apenas o contador pode estabelecer entre os tempos. A literatura de Kafka, ao invés de tentar ressuscitar a contação a partir de uma experiência coletiva já ausente, como tentaram fracassadamente alguns escritores místicos ou nacionalistas de sua época, presta tributo a ela parodiando a contagem que lhe está a mão.

Mas a estratégia narrativa de Kafka é possível porque econômica e politicamente, vale lembrar, ele está, ainda que em uma posição marginal do ponto de vista europeu, central do ponto de vista global. O que ele parodia, a burocracia estatal controlando multidões, as fábricas e sua maquinaria operada por todo um novo grupo social, a temporalidade social sincronizada por jornais e programas de rádio cotidianos, não havia chegado ainda em outros lugares do mundo, daí os recursos a estratégias temporais distintas nas periferias. A relação da literatura com as práticas culturais tradicionais é fundamentalmente diferente porque os processos históricos foram diferentes, ainda que impulsionados a partir do centro. Enquanto os modernismos europeus surgiram já num contexto de Modernidade avançada - ou seja, em sociedades profundamente modernizadas do ponto de vista da produção, com indústria, grandes massas vivendo nas cidades e transformação radical na sensibilidade e medição do tempo -, inventando a contação quase a partir do seu desaparecimento social (ainda que com base em resquícios diversos, como o Judaísmo para Kafka e Benjamin), a produção literária moderna em outros lugares do planeta surgiu de forma muito mais híbrida. Modos tradicionais de contação ainda conviveram socialmente durante muito tempo (e ainda convivem) com a forma moderna de contar e assim participam muitas vezes estrategicamente do esforço literário criativo de escapar da contagem. 
A identificação destes elementos deve ser cuidadosa para evitar generalizações e, principalmente, folclorizações: justamente o oposto do que os modos de contação são, manifestações específicas, produzidas em contextos sociais e comunitários através do tempo e das práticas materiais dos coletivos. Em A experiência do tempo no romance africano (2012), por exemplo, Sueli Saraiva analisa a temporalidade de dois romances de Boaventura Cardoso e Mia Couto não a partir daquilo que "Virginia Woolf chamou de 'discrepância entre o tempo no relógio e o tempo na mente" (2012, p. 24), ou seja, do que se chama costumeiramente de "fluxo de consciência", mas:

Entre o tempo no relógio (cronológico, linear) e o tempo nas vivências reais, permeadas pelas tradições culturais (mítico, tempo não linear). $\mathrm{Na}$ conjuntura dos romances em foco, a experiência do tempo se apresentaria, de um lado, nas demandas do chamado mundo do capitalismo tardio [...] e, por outro lado, nas situações organizadas em torno da cosmovisão mítica, do culto aos antepassados, da abolição de um tempo ilusoriamente progressivo (idem, p. 25).

A exposição de Saraiva segue com a citação de um poema de José Agualusa que vale a pena ser reproduzido justamente por retomar e reinventar positivamente um tema temporal caro ao que ela chama de “cosmovisão africana”, a circularidade do tempo:

Porque o Tempo é circular e repetido

É que tudo persiste: a ave ou o grito

O sonho ou o gesto, nada é perdido

Porque tudo em cada instante é infinito

Porque o tempo não se perde nem se gera

Nem tão pouco se corrompe ou se transforma

É que não há passado nem haverá espera

E tudo é eterno em sua efêmera forma

Por tudo isto eu sei que não existe

Deus ou Morte ou qualquer outro sentido

Aquilo que há, em isso apenas consiste

Porque o Tempo é circular e repetido

(AGUALUSA, 1990, p. 89) 
O tempo moderno, já separado dos ritmos naturais que ajudaram a formar as temporalidades não-modernas através dos séculos, um tempo que então talvez possa ser chamado de des-naturado, contrasta a tal ponto com estes ritmos que a própria experiência da repetição cíclica característica por definição de um tempo natural harmônico, se se puder falar assim - é experienciada de forma invertida. Para os não-modernos, a repetição é tradicionalmente tomada como algo positivo, como tempo em que o esperado se confirma, em que a chuva prevista permite a plantação e a colheita, em que a mulher dá à luz no período estimado, em que a caça volta a povoar adulta os campos, matas e rios, tudo isto confirmado pelas estrelas e planetas dançando em perfeita sincronia com o metrônomo cósmico. Isso faz sentido porque a organização do tempo tem fundo metafísico e narrativo, mas também econômico. A maneira de dividir o tempo é o que dita os ritmos de trabalho e define a proporção entre os dias de festa e ócio e os de trabalho ${ }^{6}$.

A interrupção do ciclo natural que se repete, ao redor do qual os coletivos estabeleceram suas práticas, como não poderia deixar de ser, é vista como catástrofe, como acontecimento falso, ilegítimo, perigoso. Daí a estrela cadente e os cometas desconhecidos serem tomados por muitas culturas como sinal de mau augúrio - eles seriam uma interrupção da ordem cósmica. Gilberto Freyre, por exemplo, cita um relato do viajante Von den Steinen que "teve ocasião de presenciar a cerimônia com que os índios do rio Xingu esconjuraram um meteoro: os baris, ou curandeiros, gesticulando com veemência e cuspindo para o ar" (1980). A própria etimologia da palavra desastre aponta para esse surgimento inesperado de uma estrela que traz inevitavelmente má sorte: prefixo pejorativo $\delta v \sigma$ - (dys) e $\dot{\alpha} \sigma \tau \dot{\rho} \rho$ (aster), estrela, etimologia que Maurice Blanchot também identifica: "Se o desastre significa estar separado da estrela (o declínio que marca o desvio quando é interrompida a relação com o acaso daquilo que vem do firmamento), ele indica a queda sob a necessidade desastrosa". (2015, p. 148)

${ }^{6}$ Esta ligação está contida já no título do poema clássico de Hesíodo, Os trabalhos e os dias, que mistura considerações éticas, narrativas míticas e ensinamentos práticos. "Quando as Plêiades filhas de Atlas se levantam no céu, / começa a colheita; quando se põem, a lavra; / por quarenta noites e dias elas / estão escondidas; e, passando o ano, de novo / aparecem pela primeira vez na época de se afiar o ferro". (2012, p. 103) 
Assim, repetir, para os não-modernos, é bom. O tempo que retorna é narrativamente o tempo da sabedoria, tempo em que o vivido, dada sua recorrência, é fonte de conhecimento sobre o futuro que nada mais é do que uma permanente releitura do passado. Daí a importância dada aos velhos em comunidades tradicionais, daí também a importância maior à memória coletiva, resguardada pelas narrativas destes velhos, em detrimento da memória e da experiência individual. Pois como não há diferença absoluta em nenhum presente em relação a todo que já passou, valem mais os relatos fundadores, quase arquetípicos, que vão do campo da história ao mítico da religião. Refletindo sobre o tempo no candomblé, Reginaldo Prandi oferece a seguinte descrição do que seria a passagem do tempo para a religião:

O tempo do mito e o tempo da memória descrevem um mesmo movimento de reposição: sai do presente, vai para o passado e volta ao presente - não há futuro. A religião é a ritualização dessa memória, desse tempo cíclico, ou seja, a representação no presente, através de símbolos e encenações ritualizadas, desse passado que garante a identidade do grupo - quem somos, de onde viemos, para onde vamos? É o tempo da tradição, da não-mudança, tempo da religião, a religião como fonte de identidade que reitera no cotidiano a memória ancestral (2001, p. 49).

Quão distinta é esta relação com a repetição moderna, para a qual o critério de tudo é o novo e o tempo cíclico é visto como tédio, como tempo da melancolia, como tempo infernal descrito por Nietzsche celebremente na doutrina do Eterna Retorno? Enquanto em certas temporalidades não-modernas o presente surge quase sempre como releitura do passado - daí, segundo Prandi, os sacerdotes fazerem suas profecias a partir de um repertório de mitos do passado que se repetiriam "envolvendo personagens do presente" (2001, p. 52) -, no tempo moderno o presente é visto sempre correndo atrás do futuro, sempre em detrimento de um futuro que regularmente aparece, com a última novidade, para envelhecer tão rapidamente quanto surgiu. Há, portanto, o tempo da repetição em que a interrupção é vista como catástrofe e o tempo da interrupção em que a repetição é vista como maldição. A fascinação da ideia de eterno retorno que tomou as nas mentes europeias do fim do século XIX, segundo Walter Benjamin em um dos fragmentos de "Parque Central", surgia justamente como um tipo de reação à 
Contagem e contação: notas sobre contar o tempo na modernidade | 43

desaparição da repetição na vida social como um todo e especificamente na economia, em função das crises capitalistas cada vez mais intensas. A repetição das crises com sua precarização continuada da vida social impediria a repetição cósmica que antes garantia a estabilidade social. Assim, a atualidade da ideia do eterno retorno "se anunciou no momento em que as condições de vida se tornaram acentuadamente instáveis devido à acelerada sucessão de crises. A ideia do eterno retorno derivava seu esplendor de já não se poder contar, em todas as circunstâncias, com o retorno da estabilidade em prazos mais curtos que os oferecidos pela eternidade" (1989, p. 156-157). Também na Origem do Drama Barroco, Benjamin sintetiza em uma imagem poderosa a mudança da representação do deus do tempo Cronos, o Saturno romano, a mudança do significado do tempo cíclico. Segundo ele:

o governante dos meses, 'o deus grego do tempo e o demônio romano das sementeiras', transformaram-se na morte ceifadora, com sua foice, que agora não visa mais os cereais, mas a espécie humana, da mesma forma que a passagem do tempo não é mais caracterizada pelo ciclo anual da semeadura, da colheita e do repouso invernal da terra, mas pelo implacável trajeto da vida em direção à morte (1984, p. 173).

Espera-se que com este percurso logo, ainda que intercalado por intervenções de disciplinas e registros diversos, tenha sido possível vislumbrar estes dois polos, estes dois modos de contar presentes e em conflito desde a ascensão da Modernidade: contagem e contação. Enquanto a primeira está associada ao tempo da fábrica, à necessidade financeira de matematizar, de igualar os acontecimentos a partir de um denominador comum, tendo como consequência justamente um horror à repetição, uma fuga constante em relação a um novo que é apenas o elemento anterior acrescentado de +1 ou -1 , a segunda é o tempo da produção coletiva orientada a partir de ritmos naturais, privilegiando a diferença entre a infinitude dos aspectos de cada acontecimento amparada em uma compreensão histórica ampla, identificando no novo o que é risco (e abertura) e o que é repetição. Estas duas descrições, é importante repetir, não são fixas, não são conceitos fechados, mas polos referenciais, posições extremas, mas vivas, móveis, e se manifestam nas mais diferentes formas cronográficas, inclusive, às vezes, acopladas uma a outra, como no exemplo da narrativa de Kafka. Se parece estranho juntar 


\section{4 | Tomaz Amorim Izabel}

do ponto de vista da temporalidade momentos célebres da literatura moderna com a resistência secular e presente de povos não-ocidentais não-modernos, como se esperou ter mostrado, a expansão e a crise da temporalidade moderna é onipresente e produz, portanto, as mais várias formas de resistências. Em outras palavras, contações contra uma única contagem. Formas de contar - com a emergência política do presente - que não sejam mais mera reprodução do tempo da produção, mas que permitam outros vislumbres do tempo: um tempo em que futuro e o passado voltem a infestar um presente aberto de possibilidades, do que não foi cumprido e do que ainda pode ser.

\section{REFERÊNCIAS}

AGUAlUSA, J. E. D. Nicolau Água Rosada e outras estórias verdadeiras e inverossimeis. Lisboa: Veja, 1990.

ALENCAR, J. Iracema. São Paulo: Scipione, 1994.

ARANTES, P. O novo tempo do mundo: e outros estudos sobre a era da emergência. São Paulo: Boitempo, 2014.

ARISTÓTElES. Metafísica. Tradução: Vicenzo Cocco. Coleção: Os Pensadores. São Paulo: Abril Cultura, 1984.

BENJAMIN, W. Charles Baudelaire. Um lírico no auge do Capitalismo. Obras Escolhidas. Volume III. Tradução: José Martins Barbosa e Hemerson Alves Baptista. São Paulo: Brasiliense, 1989.

BENJAMIN, W. Origem do Drama Barroco Alemão. Tradução: Sergio Paulo Rouanet. São Paulo: Brasiliense, 1984.

BENJAMIN, W. Rua de mão única. Obras Escolhidas. Vol. II. Tradução: Rubens Rodrigues Torres Filho. São Paulo: Brasiliense, 1987.

BERGSON, H. Os dados imediatos da consciência. Tradução: João da Silva Gama. Lisboa: Edições 70, 1988.

BLANCHOT, M. L'espace littéraire. N.R.F.: 1955.

BORGES, J. L. Ficções (1944). Tradução: Davi Arrigucci Jr. São Paulo: Companhia das Letras, 2007.

BUCK-MORSS, S. Dreamworld and Catastrophe: The Passing of Mass Utopia in East and West. Cambridge; Londres: The MIT Press, 2000.

CAMILO, V. Mito e história em Iracema: a recepção crítica mais recente. Novos estudos - CEBRAP. N. 78, pp. 169-189, julho 2007. Disponível em: <http://www.scielo.br/scielo.php?script=sci_arttext\&pid=S0101- 
Contagem e contação: notas sobre contar o tempo na modernidade | 45 $33002007000200014 \& \operatorname{lng}=e n \& n r m=i s o>$, Acesso em: 22 de maio de 2016.

CLASTRES, P. A sociedade contra o estado. Tradução: Bernardo Frey. Porto: Afrontamento, 1979.

DELEUZE, G. Diferença e Repetição. Tradução: Luiz Orlandi e Roberto Machado. Rio de Janeiro: Graal, 2006.

FREYRE, G. Casa-grande Eु senzala: formação da família brasileira sob o regime da economia patriarcal. Rio de Janeiro: José Olympio, 1980.

HESÍODO. Os trabalhos e os dias. Tradução: Alessandro Rolim de Moura. Curitiba: Segesta, 2012.

KAFKA, F. Narrativas do espólio. Tradução: Modesto Carone. São Paulo: Companhia das Letras, 2002.

KOSEllECK, R. Futuro Passado. Tradução: Wilma Patrícia Maas; Carlos Almeida Pereira. Rio de Janeiro: Contraponto; Ed. PUC-Rio, 2006.

LE GOFF, J. Memória. Enciclopédia Einaudi. Vol 1. Memória - História. Lisboa: Imprensa Nacional-Casa da Moeda, 1997.

MARX, K. O Capital. Crítica da Economia Política. Livro I. Tradução: Regis Barbosa e Flávio R. Kothe. São Paulo: Editora Nova Cultural, 1996. MAZURKEWYCZ, C. A. Chronic time, telling texts: forms of temporality in the eighteenth century. Tese, University of Iowa, 2013. Disponível online em: <http://ir.uiowa.edu/etd/2578 em 24/05/2017>.

NOYS, B. Malign Velocities. Accelerationism and Capitalism. Winchester, UK; Washington, USA: Zero Books, 2014.

PRANDI, R. O candomblé e o tempo: concepções de tempo, saber e autoridade da África para as religiões afro-brasileiras. RBCS. Vol. 16, n. 47, pp. 43-58, outubro 2001.

SARAIVA, S. Boaventura Cardoso, Mia Couto e a experiência do tempo no romance africano. São Paulo: Terceira Margem, 2012.

SCHWARCZ, L. Questões de fronteira: sobre uma Antropologia da história. Revista Novos estudos - CEBRAP. N. 72, pp.119-135, julho de 2005.

SHERMAN, S. Telling Time: Clocks, Diaries, and English Diurnal Form, 1660 1785. Chicago: The University of Chicago Press, 1996.

SIMMEL, G. Filosofia do dinheiro. Tradução: Antonio C. Santos. Manuscrito. Pereira, 2012.

SIMMEL, G. O dinheiro na cultura moderna, In: SOUZA, J.; ÖELZE, B. (Orgs.). Simmel e a Modernidade. Brasília: UnB, 1998. 


\section{6 | Tomaz Amorim Izabel}

THOMPSON, E. P. Tempo, disciplina de trabalho e capitalismo industrial. In:_____. Costumes em comum. Tradução: Rosaura Eichemberg. São Paulo: Editora Schwarcz, 1998.

WEBER, M. A ética protestante e o "espírito" do capitalismo. Tradução: M. Irene de Q. F. Szmrecsányi; Tamás J. M. K. Szmrecsányi. São Paulo: Pioneira Thomson Learning, 2001.

Recebido em: 25/08/2019

Aceito em: 14/09/2019 